\title{
Atuais desafios e perspectivas da Associação Nacional de Pesquisa e Pós-Graduação em Ciência da Informação (Ancib)
}

\section{Entrevista:}

Joana Coeli Ribeiro Garcia

Doutora em ciência da informação pela Universidade Federal do Rio de Janeiro (UFRJ)/Instituto Brasileiro de Informação em Ciência e Tecnologia (Ibict), Rio de Janeiro, RJ, Brasil. Professora do Departamento de Ciência da Informação da Universidade Federal da Paraíba, João Pessoa, PB, Brasil. Presidente da Associação Nacional de Pesquisa e Pós-Graduação em Ciência da Informação (Ancib), João Pessoa, PB, Brasil.

E-mail:nacoeli@gmail.com

\section{Entrevistadoras:}

Luciana Ferreira da Costa

Mestre em ciência da informação pela Universidade Federal da Paraíba (UFPB). Professora do Departamento de Ciência da Informação da Universidade Federal da Paraíba, João Pessoa, PB, Brasil.

E-mail: lucianna.costa@yahoo.com.br

\section{Terezinha Elisabeth da Silva}

Doutora em multimeios pela Universidade Estadual de Campinas (Unicamp), Campinas, SP, Brasil. Professora do Departamento de Ciência da Informação da Universidade Estadual de Londrina, Londrina, PR, Brasil.

E-mail: telis@uel.br

\section{APRESENTAÇÃO}

\section{Emir José Suaiden}

Doutor em ciência da informação pela Universidad Complutense de Madrid (UCM), Madrid, Espanha. Professor do Departamento de Ciência da Informação e Documentação da Universidade de Brasília, Brasília, DF, Brasil. Diretor do Instituto Brasileiro de Informação em Ciência e Tecnologia (Ibict), Brasília, DF, Brasil.

E-mail:emir@ibict.br

Uma classe forte é uma classe que se destaca não somente por envolver os seus profissionais, mas, principalmente, por criar condições adequadas de fortalecimento e visibilidade que facilitem o desempenho da responsabilidade social e a inclusão em políticas públicas.

\author{
No Brasil, citamos o \\ grande exemplo da \\ Federação Brasileira \\ de Associações de \\ Bibliotecários, Cientistas \\ da Informação e \\ Instituições (Febab) que, \\ em 1962, teve aprovada \\ a Lei do Bibliotecário. \\ As reuniões da American
}

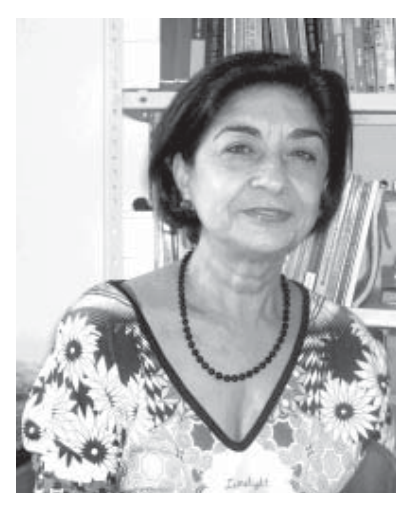
Library Association chegam a agregar mais de 30 mil profissionais, e a associação é responsável pela ampla interação da biblioteca com a comunidade, fator essencial na política de informação.

Desde que foi fundada, a Associação Nacional de Pesquisa e Pós-graduação em Ciência da Informação (Ancib) tem se destacado na demonstração das potencialidades da ciência da informação no Brasil, além de ser a porta-voz da classe nos diálogos com as agências de fomento.

Outro fato exemplar é que, graças ao trabalho da Ancib, a produção científica brasileira, na área da Ciência da Informação, tem obtido aumento qualitativo extraordinário e com um reflexo na visibilidade internacional.

No momento em que se encerra o mandato de Joana Coeli Ribeiro Garcia na Presidência da Ancib, é oportuno ressaltar sua valiosa contribuição ao progresso e fortalecimento da Associação.

No registro dessa contribuição, apresentamos esta entrevista com Joana Coeli, realizada em iniciativa conjunta pelas professoras Luciana Ferreira da Costa (UFPB) e Terezinha Elisabeth da Silva (UEL). 


\section{ENTREVISTA}

Luciana - Com 21 anos de existência, a Associação Nacional de Pesquisa e PósGraduação em Ciência da Informação (Ancib) tem por objetivo "promover o desenvolvimento da pesquisa e de estudos avançados da ciência da informação no país", citando o seu estatuto. Iniciando esta entrevista, como a senhora avalia a contribuição desta sociedade científica para a CI, desde sua fundação?

Joana Coeli Ribeiro Garcia - Congregar instituições, pesquisadores, estudantes de pósgraduação e profissionais egressos da pósgraduação em ciência da informação e áreas afins é a missão da Associação Nacional de Pesquisa e Pós-Graduação em Ciência da Informação e Biblioteconomia. Tal associação oportuniza discutir e refletir sobre os resultados das pesquisas que o grupo realiza e apresentar novas possibilidades para a pós-graduação. Ao fazermos um retrospecto, é possível perceber que a Associação está consolidada. O Fórum de Coordenadores tem atuação decisiva na condução da Ancib, e os programas estão paulatinamente subindo seus conceitos junto à Coordenação de Aperfeiçoamento de Pessoal de Nível Superior (Capes). Nos últimos tempos, o Encontro Nacional de Pesquisa em Ciência da Informação (EnAncib) realiza-se anualmente, agora com dez grupos de trabalho (GT) e mínimo de 15 comunicações de pesquisa por GT. No primeiro evento, 36 resumos de pesquisas foram apresentados, início que deve ser enaltecido pois nos conduziu ao que somos. Isso nos leva a admitir que os horizontes se alargaram e que a Ancib se firmou como a Associação Científica da área da ciência da informação, inclusive com a Capes pontuando os trabalhos, reconhecendo que as comunicações feitas nos EnAncibs representam a produção de conhecimento da área. Nossos sócios lidam com teorias e metodologias que ampliam o conhecimento em ciência da informação; mantêm nossos programas de pós-graduação e criam programas novos, perseguindo conceitos mais elaborados, sinônimo de muito trabalho e persistência; atendem às demandas de alunos de graduação e pós-graduação no que se refere às disciplinas e à orientação de trabalhos de graduação, iniciação científica, mestrado e doutorado; respondem às demandas das editorias de revistas, dos conselhos ad hoc e das agências de fomento; respondem aos editais de financiamento à pesquisa e de bolsas de produtividade para alcançar níveis significativos de produção científica. Somos competentes em todas essas atividades, o que não significa dizer que a ciência da informação está pronta, ou que tudo na Ancib esteja feito. Cada diretoria pode e deve fazer mais por sua associação, e falta-nos a inserção internacional para alcançarmos patamares mais elevados. Os grandes pensadores nos lembram que sempre há algo a ser feito e sempre se pode fazer melhor, aprendendo com as experiências do passado. Nisso reside a sabedoria.

Terezinha Elizabeth - Como se deu a sua candidatura à Presidência da Ancib? Gostaríamos que a senhora registrasse quais foram as motivações para tal empreitada.

Joana Coeli - Participamos sempre das reuniões da Ancib. Algumas vezes, como coordenadora do Curso de Mestrado em Ciência da Informação da Universidade Federal da Paraíba - era essa a denominação na época - noutras, como coordenadora do grupo para apresentação de proposta de curso novo junto à Capes. Reafirmávamos que o Nordeste necessita concorrer com as demais regiões, como o Programa Nacional de Pós-graduação expressa claramente. Numa das reuniões em que não estávamos presentes, fomos surpreendidas com o telefonema de alguns participantes sobre a possibilidade de candidatura à Ancib. Aceitamos, somente perguntando se a vice-presidente à época, a Doutora Lígia Café, não teria intenções de concorrer, pois entendíamos ser esse o caminho natural. Com a negativa ao questionamento, abraçamos a causa, antevendo os desafios, mas, sobretudo, a possibilidade de a Ancib ter sua primeira diretoria no Nordeste, com a pretensão de realizar algo em prol da ciência da informação. A resposta tem algo de muito pessoal, de nordestina, de demonstrar que temos iguais condições aos profissionais de outras 
regiões. Reconhecemo-nos com verdade, emoção e transparência, se é que uma descendente de negros e árabes pode ser translúcida. Queremos deixar claro que falamos de coração aberto.

Luciana - Sobre sua gestão como presidenta da Ancib, no biênio 2008-2010, que propostas foram implementadas e quais os desafios enfrentados durante o período da gestão? Que pontos positivos e negativos merecem ser destacados?

Joana Coeli - As metas que propusemos quando de nossa candidatura e que conseguimos realizar podem ser resumidas nas seguintes: garantimos a continuidade do Fórum de Coordenadores de Pós-graduação em CI e a presença da Capes e do Conselho Nacional de Desenvolvimento Científico e Tecnológico (CNPq) nas reuniões da área; intensificamos o entrosamento entre CI $x$ áreas afins $x$ estudiosos interessados no campo da informação; promovemos campanha para ampliar a rede de sócios, que passou de 83 pagantes, em 2008, para 96, em 2009, e 110 anuidades pagas no ano de 2010, até o momento desta entrevista; cadastramos as instituições com as quais os programas de pós-graduação mantêm convênio, em âmbito nacional e internacional, com o intuito de garantir a participação da Ancib em ações de interesse dos programas; editamos dois números da revista técnico-científica. Tendências da Pesquisa Brasileira em Ciência da Informação, como instrumento de divulgação da produção intelectual da área, e estabelecemos os contatos com a ProQuest para inseri-la nas bases de dados que indexam a área da ciência da informação; revimos o conteúdo dos documentos-base da Ancib - estatuto e regimento -, sugerindo mudanças necessárias, quando da Assembleia Geral do XI EnAncib; organizamos os Arquivos da associação pelas modernas técnicas da arquivística; criamos comissões por meio das quais se elaborou uma série de documentos que orientam a condução da Ancib e que podem ser usados pelos coordenadores de programas de pós-graduação para alcançar a internacionalização da área; atualizamos o portal da Ancib, no qual inserimos os sites dos EnAncib desde 2007 e os textos de 744 trabalhos apresentados desde o IV EnAncib. Se pensarmos que o primeiro ano foi todo despendido com burocracia de Receita Federal, Cadastro Nacional de Pessoa Jurídica, registros em cartório, atendimento de documentos para formar dossiê no Banco do Brasil para abertura de contas etc., etc., temos um saldo alvissareiro. Há, contudo, metas que não conseguimos realizar, mas o que importa registrar é a participação inconteste da secretária geral, doutora Maria das Graças Targino, do vice-presidente doutor. Valdir Morigi, do Fórum de Coordenadores e dos coordenadores de GT, que tiveram atuação ímpar durante os dois anos em que dirigimos a Entidade, sem os quais teríamos sido um galo sozinho tentando tecer uma manhã.

Terezinha Elizabeth - Que papel desempenha a presidência da Ancib no fórum dos coordenadores de pós-graduação da área? Quais interações têm sido feitas?

Joana Coeli - Pelo Estatuto, o Fórum de Coordenadores tem por finalidade assessorar a Diretoria Executiva. Nossa gestão usou a prerrogativa das comissões formadas por componentes do Fórum, incluindo outros docentes que deveriam: 1) mapear as áreas de CI, Arquivologia, Biblioteconomia e Museologia; 2) identificar instituições/pesquisadores nacionais e estrangeiros; 3) identificar as possibilidades de capacitação de pessoal; 4) estudar a assimetria entre as áreas nos Comitês da Capes; 5) estabelecer diretrizes para editoração de livros e revistas; 6) apresentar condições para a profissionalização da Ancib; 7) apresentar proposta para realização dos EnAncib; 8) sugerir áreas e temáticas para a pesquisa na CI, dentre outras atribuições. Como se pode perceber, das metas que conseguimos alcançar, grande parte do que está aqui pontuado foi realizado. Isso se deve a um esforço grande dos que se comprometeram. Algumas comissões não chegaram a concluir o trabalho, e são diversos os fatores que justificam esse fato. Por dever, destacamos que cada nova atribuição acrescenta nova carga de atividades ao que cada um exerce. E existem limitações humanas. Acreditamos que a relação de todos, entre si e com a diretoria, foi produtiva e satisfatória. O que realizamos culminará 
com o livro Associação Nacional de Pesquisa e PósGraduação em Ciência da Informação (Ancib): reflexão e proposta para maior dinamização, no qual tais produções estão explicitadas. A publicação se encontra no prelo e brevemente a enviaremos aos sócios da Ancib.

Luciana - Talvez um dos maiores problemas da pesquisa e da pós-graduação no Brasil seja relativo ao distanciamento que existe entre os programas e os órgãos de fomento e de avaliação. Como a Ancib tem trabalhado para diminuir esta distância? Tendo, a senhora, citado a Capes e o $\mathrm{CNPq}$, há efetivamente trabalho integrado da Ancib com estas instituições?

Joana Coeli - Vamos entender que agências de fomento tanto nos estimulam e financiam, quanto determinam os caminhos a seguir. Também vamos concordar que cada ser humano é diferente, seja no aspecto pessoal, no intelectual, ou nas atitudes. Lembro de uma reunião das Ciências Sociais Aplicadas I, em que se anunciou a fala do presidente da Capes. Honra e oportunidade de diálogo com a área. Ele veio, fez o discurso, levantou-se e saiu nos dizendo que tinha outros compromissos. Mas, independentemente desse evento fortuito, nossas relações têm sido cordiais com o doutor Marcius Freire, coordenador das Ciências Sociais Aplicadas I, e com a doutora Ida Stumpf, coordenadora adjunta desta área. O mesmo também ocorre com a doutora Maria Nélida González de Gómez, representante titular da ciência da informação junto ao Comitê Assessor do Conselho Nacional de Desenvolvimento Científico e Tecnológico (CA/ $\mathrm{CNPq}$ ) e com o doutor José Augusto Guimarães, representante adjunto do CA/CNPq. Tanto que incentivou a Ancib a solicitar expressamente à Capes ações que garantam a inserção da ciência da informação em outros países, estimulando o pós-doutorado dos docentes no exterior, para dar força às reivindicações dos nossos sócios. Ao $\mathrm{CNPq}$, garantia da presença da Ancib nas reuniões daquela instituição, especificamente quando tratar de itens de interesse da área, tais como políticas internas e externas direcionadas à pós-graduação e a atividades de pesquisa; bem como a possibilidade de editais que contemplem bases de dados, repositórios e repertórios documentais, que forneçam informações que possam respaldar e estimular o desenvolvimento de pesquisas na área.

Terezinha Elizabeth - Diante da publicação da nova avaliação trienal da Coordenação de Aperfeiçoamento de Nível Superior (Capes) para os cursos de pós-graduação stricto sensu recomendados no país, conforme a senhora citou no início da entrevista, como se encontra, em sua opinião, a pós-graduação em ciência da informação no Brasil?

Joana Coeli - Ao verificarmos os resultados da última avaliação, reafirmamos que a área encontra-se na sua maturidade. Foram quatro programas com conceito cinco; seis programas com conceito quatro, e a UFPE e a UEL com conceito três. Estes últimos programas não completaram o triênio para inserir em seu relatório. Importa mencionar que o da UEL é o único mestrado profissional da área da ciência da informação. Como referimos, em geral os conceitos indicam que estamos atendendo aos critérios que foram estabelecidos para nos avaliarmos. Avaliarmo-nos, porque não há como esquecer que somos avaliados por nossos pares. Há, porém, uma situação a que devemos nos referir. Carlos Matus, ex-Ministro do Planejamento de Salvador Allende, diz que, quando se têm números para analisar, eles se apresentam ao avaliador como um cubo. A depender do lugar onde o avaliador esteja, uns lados do cubo aparecem e outros ficam escondidos; assim os números são interpretados, pelo lado que o avaliador os vê. O que fica invisível e não está na letra fria dos relatórios é o esforço das equipes para alcançaros critérios exigidos e obter notas mais altas. Os membros (ou pares) que participam de reuniões e discussões com os coordenadores acompanham e conhecem o que está se realizando. E são eles que fazem a primeira avaliação, a avaliação da área. Não há justificativa para não acatar a decisão da área, e modificá-la. Não podemos fechar os olhos e fazer de contas que nada aconteceu. Não podemos fechar os olhos e fazer de contas que os avaliadores da 
Atuais desafios e perspectivas da Associação Nacional de Pesquisa e Pós-Graduação em Ciência da Informação (Ancib)

área foram respeitados em suas avaliações, quando se abaixa uma nota dada por eles. Afinal, a área é composta por aqueles coordenadores que convivem com os programas, ou, em outras palavras, os que veem o invisível esforço das equipes.

Luciana - Nesse sentido, professora Joana, qual o posicionamento em relação à avaliação da pós-graduação pela Capes e ao sempre polêmico sistema Qualis de Periódicos e Livros?

Joana Coeli - Avaliar não é uma atividade das mais prazerosas para nenhum dos lados, nem para o que faz nem para aquele que recebe. Mas é parte integrante da mudança, da correção, da melhoria, do avanço. Parece ser o carma de quantos abraçam a atividade acadêmica. É bem verdade que, para uns, deve ser prazeroso. Mas, estando de um lado ou de outro, não podemos esquecer o que dizem os critérios. Em um programa, 30\% do seu conceito estão vinculados à formação docente e à composição do quadro do programa. Outros $30 \%$ a $35 \%$, à sua produção científica e/ou tecnológica. Finalmente, 30\% pertencem aos discentes, incluindo-se teses e dissertações concluídas, ou seja, a competência do docente em levar o aluno a termo. Assim, não há como discordar de que mais ou menos $90 \%$ da avaliação de um programa são responsabilidade docente. Incluindose aqui o quesito mais importante, qual seja, o de produção, que nos obriga a uma corrida desenfreada pelos periódicos mais bem conceituados. E para atender aos critérios dos periódicos, os editores (nossos pares) recusam artigos com alunos, recusam artigos com determinado número de coautores, recusam e recusam, diminuindo nossas possibilidades de publicação. Mas, contrariamente, haveria a possibilidade de não avaliar? Esta seria pior do que aquela que nos referimos, pois a inexistência de critérios daria margem a atitudes inescrupulosas. A inexistência de avaliação não nos estimularia a atingir os critérios. Nessas situações, incluímos também o Qualis de periódicos e livros, que se torna a cada dia mais rigoroso, mas que, ao atingirmos seus níveis A1 e A2, conseguimos a circulação internacional, o que é benfazejo para nossos programas. Como falamos, avaliar é sempre um dilema, qualquer dos lados pode ser bom ou ruim, dependendo do contexto. Quem tem conceito bom quer que a avaliação se realize em espaços de tempo mais longos, para manter o status quo; quem não tem, deseja avaliação com tempos mais reduzidos para sair de um conceito desagradável.

Terezinha Elizabeth - Aproveitando, a oportunidade, gostaríamos de ressaltar a idealização e publicação da revista Tendências da Pesquisa Brasileira em Ciência da Informação. A senhora poderia comentar sobre as origens, a proposta deste periódico e sua importância para a CI?

Joana Coeli - A revista da Ancib, não exatamente esta, foi pensada durante reunião em Santa Catarina, quando era presidenta a doutorada Regina Maria Marteletto. Por razões que não nos compete discutir, ela não conseguiu operacionalizar a proposta. Ao assumir a Ancib, a doutora Marisa Brascher criou a Tendências da Pesquisa Brasileira em Ciência da Informação, com o propósito de, assemelhando-se ao Annual Review of Information Science and Technology (Arist), focalizar atividades e tendências da ciência da informação e ser constituída por artigos de revisão. Então, é um periódico com uma proposta que ainda não temos no Brasil. Reafirmo que, igualmente à nossa companheira de diretoria que nos antecedeu, temos tentado, e no plural, destacando a gestão da doutora Maria das Graças Targino, que a revista seja, prioritariamente, formada por artigos de revisão. Ainda não conseguimos o feito. Entretanto, publicamos dois números e, no momento, negociamos com a ProQuest para inseri-la em diversas bases de dados que indexam a ciência da informação, como citamos anteriormente. A publicação é anual, organizada em capítulos temáticos, do tipo revisão ou estado-da-arte, que reúnem e analisam pesquisas brasileiras publicadas no campo da ciência da informação, objetivando oferecer aos leitores um retrato de cada tópico escolhido. Os textos são escritos por autor ou grupo de autores, especialmente convidados pelo editor, porém submetidos à avaliação peer review, para 
garantir sua cientificidade. Temos tentado focalizar em artigos de revisão e em tendências, isso porque nenhum periódico brasileiro da CI cumpre esse papel, e aí reside sua importância. Por tal razão, um número a cada ano, exatamente porque esse tipo de artigo oferece mais trabalho que qualquer outro.

Luciana - Agora uma questão sobre a relação da Ancib com certamente a mais importante instituição dedicada à informação científica e tecnológica do país, o Instituto Brasileiro de Informação em Ciência e Tecnologia (Ibict). Qual diálogo ou cooperação se mantém entre as duas instituições diante de suas responsabilidades e papéis políticos?

Joana Coeli - Desde que assumimos a Ancib, o Dr. Emir Suaiden é o diretor do Ibict. Ele foi aluno da primeira turma do Curso de Mestrado em Ciência da Informação da Universidade Federal da Paraíba, e sua dissertação foi a primeira a ser defendida e aprovada. Desde os tempos em que era do Instituto Nacional do Livro, mantemos um bom relacionamento. O portal da Ancib e a Tendências da Pesquisa Brasileira em Ciência da Informação estão hospedados no Ibict. Podemos afirmar que, sempre que ocorrem demandas seja da Ancib, seja do Ibict, estamos, de parte a parte, dispostos a oferecer nossas contribuições institucionais. Ele esteve recentemente em João Pessoa, convidado a abrir o Encontro Nacional dos Estudantes de Biblioteconomia, Documentação, Gestão e Ciência da Informação (Enebd) e, como sempre, representou muito bem sua instituição. Por solicitação dele, revisamos o conteúdo do documento Metodologia para avaliação de produtos e serviços de informação, uma publicação do Ibict, de autoria de Eliana da Conceição Rocha e Márcia de Figueiredo Evaristo de Sousa. Estivemos juntos apoiando o Colóquio Mediações e Usos de Saberes e da Informação: um diálogo França-Brasil (Rede MUSSI), que ocorreu no Rio de Janeiro, em novembro de 2008. E, novamente, estaremos na mesa de abertura do XI EnAncib, que ocorrerá na cidade do Rio de Janeiro, entre 25 e 28 de outubro de 2010.
Terezinha Elizabeth - Citando o Encontro Nacional de Pesquisa em Ciência da Informação (Enancib), gostaríamos que a senhora discorresse sobre a importância deste encontro para a Ciência da Informação no Brasil.

Joana Coeli - Como disse, é evidente que a pesquisa da área está representada nos trabalhos dos dez Grupos de Pesquisa. Também referi que, no primeiro evento, foram apresentados 36 resumos. O portal da Ancib registra 744 trabalhos desde o IV EnAncib. Ainda não inseridos os do XI EnAncib e, por uma questão de indisponibilidade do material em formato eletrônico, também os resumos e/ou comunicações de pesquisa dos três primeiros EnAncib. No X EnAncib, vocês recordam, falávamos dos pesquisadores e dos coordenadores dos cursos de pós-graduação em ciência da informação, que se reuniam para discutir os problemas que afetavam suas singularidades, tentando encontrar um veio comum que o compartilhamento e a união proporcionam e fortalecem, sem estar organizados em torno de uma associação. A Paraíba sediou dois desses encontros e, após a existência da Ancib, realizou uma reunião congregando pesquisadores do Norte e do Nordeste, especialmente dos Estados do Pará, Maranhão, Pernambuco, Bahia e Paraíba, com a finalidade de conhecer a diversidade dos programas e das pesquisas desenvolvidas e intercambiar experiências com esses estados. Essa tem sido a tônica dos EnAncib, conhecer o que se pesquisa e, por meio da discussão, ampliar as pesquisas e fortalecer os PPGCIs. Em outras palavras, fortalecer a ciência da informação. O EnAncib tem, como costumamos falar no nosso nordestinês, um grande mote - as pesquisas apresentadas aos Grupos de Trabalhos sob a forma de comunicação e de pôsteres. O EnAncib é, pois, o fórum de debates próprios à atividade de pesquisa da Ciência da Informação. Com uma nova tarefa a abraçar, necessitamos tornar o que fazemos no Brasil conhecido em outros espaços geográficos.

Ci. Inf., Brasília, DF, v. 39 n. 1, p.125-131, jan./abr., 2010 
Luciana - João Pessoa foi a segunda cidade do nordeste a receber o Enancib, em sua última edição no ano de 2009. Sabemos das dificuldades que um evento como este representa. A senhora poderia comentar sobre esses desafios e sobre a importância do Enancib para o Programa de Pós-Graduação em Ciência da Informação (PPGCI) da UFPB, além das expectativas para a próxima edição, a $11^{a}$, a ser realizada no Rio de Janeiro sob a organização do PPGCI do convênio entre o Ibict e a Universidade Federal do Rio de Janeiro (UFRJ)?

Joana Coeli - Antes de João Pessoa, Salvador havia realizado um EnAncib. Naquela cidade, na condição de vice-coordenadora do Programa, lançamos a capital da Paraíba para sediar o X EnAncib. Claro que os desafios foram grandes, do tamanho de somente dois voos domésticos diários para João Pessoa e uma universidade em reconstrução. A despeito disso, a João Pessoa acorreram mais ou menos 500 pesquisadores da ciência da informação, com tanta boa vontade e disposição, que não viram ou não quiseram ver os problemas que vivenciávamos. Aqui foram apresentadas 195 comunicações orais, além de pôsteres sobre o que têm realizado em pesquisas e, ao mesmo tempo, debatendo perspectivas, tendências e caminhos a serem adotados e seguidos. São indicadores que resultam do credenciamento de novos programas, da ampliação de grupos de trabalho e, consequentemente, dos associados da Ancib. Isso deu alento à Ancib que, prontamente, acatou sugestão do Fórum de Coordenadores dos Programas de Pós-graduação, instituindo uma comissão da qual fizeram parte Edmir Perroti, Marta Pomim Valentim, Graça Targino e eu, para elaborar um documento orientador dos próximos encontros. O Programa do IBICT/UFRJ está usando-o no XI EnAncib e, ao que tudo indica, com melhores condições do que nós tivemos. Mas não queremos afirmar que o sucesso do XI EnAncib se deva somente a esse documento, isso seria cabotinagem e desconhecimento das competências que lá se encontram instaladas. Somente pretendemos reafirmar a relação de compartilhamento entre os preparativos do evento e a Ancib, de troca de informações e de mútua ajuda.

Terezinha Elizabeth - Encerrando a entrevista, quais seriam, em sua opinião, as perspectivas para a ciência da informação no Brasil e de que forma a Ancib se posiciona em face dessas perspectivas?

Joana Coeli - A Capes divulgou o resultado da avaliação do triênio 2007, 2008 e 2009, em setembro de 2010. Toda a área acadêmica tomou conhecimento de o quanto a ciência da informação cresceu durante os últimos três anos. Isso deixa a todos, docentes e discentes, com o moral elevado e com muita motivação para seguir em frente, buscando atingir um nível mais alto. Foram dois programas que, no primeiro triênio, mudaram para conceito quatro: Museologia/Unirio e PPGCI/ UFPB. Isso significa muito trabalho realizado. Há alguns senões sobre a avaliação que, com certeza, serão solucionados. Como citado anteriormente, na Ancib trabalhamos com várias comissões, uma das quais mapeou as universidades estrangeiras, e outra, os pesquisadores estrangeiros que se interessam pela área aos quais, com certeza, busca-los-emos para atingir visibilidade internacional. Acreditamos que essa é a meta a ser perseguida pela Ancib e pelos programas de pós-graduação, parte integrante da Ancib. De outra parte, os GTs e as pesquisas divulgadas também crescem a cada ano e com isso imprimem avaliação mais rigorosa pelas agências de fomento. O que é saudável e muito bom para a área.

Entrevista concedida a Joana Coeli Ribeiro Garcia e Luciana Ferreira da Costa em 15/09/2010.

Artigo submetido em 08/10/2010. 